\title{
ADOECIMENTO PSÍQUICO EM ATLETAS DE ALTO RENDIMENTO: A IMPORTÂNCIA DA PSICOLOGIA DO ESPORTE
}

\section{Psychic disease in high performance athletes: the importance of sport psychology}

\author{
Luane de Jesus Frades -UNIFIMES/Brasil \\ Evandro Salvador Alves Oliveira -UNIFIMES/Brasil \\ Bruno Manchini Varoli - Universidade de Londrina/Brasil \\ Cíntia de Moraes Cabreira Carneiro - UNIFIMES/Brasil
}

\begin{abstract}
RESUMO: O psicólogo do esporte auxilia indivíduos na preparação psicológica antes e após as competições, e a atuação do mesmo acontece visando a busca de bem-estar físico e psicológico dos atletas. Nesse sentido, o tema abordado neste artigo discute a importância do psicólogo no universo esportivo, no sentido de destacar a atuação deste profissional na vida de atletas de alto rendimento. O objetivo principal é discutir a importância da atuação do psicólogo do esporte no trabalho com atletas de alto rendimento. Trata-se de uma investigação inspirada na abordagem qualitativa, construída a partir de uma revisão bibliográfica e sistemática, que contou com a análise e a interpretação de dados científicos produzidos nos últimos anos por teóricos que discutem a temática aqui anunciada. Como conclusões, destaca-se que o psicólogo do esporte, cada vez mais, conquista espaço no ambiente esportivo por realizar importantes intervenções que auxiliam atletas e equipes de competições a compreenderem os entraves e, sobretudo, criar saídas e alternativas que transformam positivamente as dificuldades do cotidiano. Além disso, esse profissional pode previnir doenças psíquicas, pois ele atua de maneira a intervir no trabalho que envolve necessidades de resultados que, por vezes, ocorre sob pressão sofrida por atletas, o que pode levar ao adoecimento psíquico de tais sujeitos.
\end{abstract}

Palavras-chave: Adoecimento psíquico. Psicologia do esporte. Intervenção psicológica.

ABSTRACT: The sports psychologist assists individuals in psychological preparation before and after competitions, and the performance of the same happens aiming at the search for physical and psychological well-being of athletes. In this sense, the theme addressed in this article discusses the importance of the psychologist in the sports universe, in order to highlight the performance of this professional in the lives of highperformance athletes. The main objective is to discuss certain potentialities arising from sport psychology that permeate the context of athletes. It is a research inspired by the qualitative approach, built from a bibliographic and systematic review, which relied on the analysis and interpretation of scientific data produced in recent years by theorists who discuss the theme announced here. As conclusions, it is highlighted that the sport psychologist, increasingly, gains space in the sports environment by performing important interventions that help athletes and competition teams to understand the obstacles and, above all, create solutions and alternatives that positively transform the difficulties of the sport. daily. In addition, this professional can prevent psychic diseases, as he acts in a way to intervene in work that involves results needs that sometimes occur under pressure suffered by athletes, which can lead to the psychic illness of such subjects.

Educação, Psicologia e Interfaces, Volume 4, Número 3, p. 1-16, Julho/Setembro, 2020.

ISSN: 2594-5343. DOI: 10.37444/issn-2594-5343.v4i3.297 
Keywords: Psychic illness. Sport psychology. Psychological intervention.

\section{INTRODUÇÃO}

A Psicologia do esporte é a ciência do treinamento esportivo que tem proporcionado importantes contribuições para a otimização da performance de atletas e equipes. Existem vários fatores que influenciam os significativos resultados que acontecem no mundo esportivo. Dentre esses fatores o trabalho psicológico com os atletas é um ponto a ser considerado e melhor investigado.

$\mathrm{Na}$ pretensão de explorar as potencialidades que esse tipo de trabalho possibilita, procuramos abordar algumas questões, por exemplo: como atletas de competição lidam com a questão psicológica, principalmente em relação a competições muito importantes? Partimos do pressuposto de que há cobranças elevadas por resultados, o que interfere em outros pontos, como fatores emocionais, dentre outros aspectos que são exigidos, proporcionando o aparecimento de adoecimento psíquico.

Embasamo-nos em autores que se dedicam a estudar o objeto aqui trabalhado, ou seja, a atuação do psicólogo do esporte no esporte de alto rendimento, dentre eles, destacamos: Galatti (2010), Weinberg e Gould (2017), Pesca e Cruz (2011), Casal (2007), entre outros.

Neste artigo procuramos discutir questões sobre atletas de alto rendimento e a Psicologia do esporte, e também apresentar discussões baseadas em situações vivenciadas durante a Copa do Mundo de 2014 e a Olimpíadas de 2016, grandes eventos esportivos realizados no Brasil (duas odisséias) nesta década, que trazem como pano de fundo o relato de atletas que sofreram com adoecimento psíquico.

Entendemos que o profissional da Psicologia esportiva necessita amparar psicologicamente os atletas e por isso acreditamos o quanto é necessário atentar-se a este enfoque. Isto deve ser considerado quanto as orientações sobre alimentação balanceada, programada por nutricionistas, por exemplo, entre outras questões. Nesse aspecto, corpo e mente são dimensões distintas e indissociáveis importantes. Cuidar do corpo significa também percebê-lo como um todo unificado, do qual fazem parte emoções e estruturas mentais - e por esta razão nos preocupamos também com esta dimensão.

Educação, Psicologia e Interfaces, Volume 4, Número 3, p. 1-16, Julho/Setembro, 2020.

ISSN: 2594-5343. DOI: 10.37444/issn-2594-5343.v4i3.297 
Vale ressaltar um ponto importante nesta introdução, pois o que determina a vitória ou a derrota de um atleta profissional não é apenas suas habilidades técnicas. $\mathrm{O}$ aspecto psicológico é uma questão fundamental no meio esportivo, para atingir o seu êxito profissional, embora nem todo atleta realmente dê tanta relevância para isso. Por esta razão começaremos a abordar algumas discussões que dizem respeito ao esporte de alto rendimento.

Sendo assim, o objetivo nuclear deste artigo foi construído com o seguinte intuito: discutir a importância da atuação do psicólogo do esporte no trabalho com atletas de alto rendimento. Vale lembrar que toda investigação científica nasce de algum tipo de problema (pergunta) e, a partir dele, surgem alguns objetivos e caminhos metodológicos a serem percorridos. Desse modo, julgamos pertinente destacar que o nosso problema é saber: em que aspecto o profissional da psicologia do esporte é capaz de intervir consideravelmente nos resultados de atletas esportivos?

Dessa maneira, a partir das ambições acima (objetivo e problema), destacamos que o trabalho em questão expressa relevância social e científica pelo fato de possibilitar a construção de algumas compreensões sobre a interação que ocorre entre mente e corpo, que, em nossa perspectiva, são indissociáveis para a vida do ser humano.

\section{MATERIAL E MÉTODO}

Este trabalho foi construído tendo em vista os pressupostos da abordagem qualitativa, com vistas a elaboração de uma revisão bibliográfica e sistemática. Alicerçamos nesse tipo de abordagem em razão de nos interessarmos pela essência e aspectos que a perspectiva qualitativa permitem analisar. Ou seja, as compreensões e reflexões que os estudos dos autores aqui mencionados apresentam. Tais compreensões colaboram para as análises e discussões que aqui são delineadas.

As produções científicas selecionadas para compor a análise dos dados obedecem o recorte temporal dos últimos 20 anos, isto é, de 1999 a 2019. Referem-se a textos bibliográficos publicados nos formatos de artigo científico, livros e dissertações de mestrado. As palavras-chave utilizadas para as buscas foram as seguintes: psicologia do esporte; esporte de alto rendimento e psicologia do esporte; e atuação do psicológo do esporte em equipes de competição.

Os critérios de inclusão foram: produções publicadas nos últimos 20 anos; que 
Luane Luane de Jesus Frades, Evandro Salvador Alves Oliveira, Bruno Manchini Varoli \& Cíntia de Moraes Cabreira Carneiro

apresentassem em seus títulos, ou resumos, as palavras-chave. E os critérios de exclusão foram os seguintes: pesquisas quantitativas; textos publicados fora do recorte temporal selecionado.

Os trabalhos selecionados para a análise permitiram construir as subseções a seguir, que foram organizadas objetivando discutir, respectivamente, o esporte de alto rendimento, o panorama geral sobre a psicologia do esporte no Brasil, o esporte como fenômeno social, a influência da mídia na cultura do esporte brasileiro, bem como o adoecimento psíquico e, por fim, as contribuições do psicólogo no âmbito esportivo.

\section{ESPORTE DE ALTO RENDIMENTO E PSICOLOGIA: ALGUMAS PECULIARIDADES}

O esporte de alto rendimento ou de alta performance é aquele cuja finalidade é de se preparar fisicamente e psicológicamente para determinada modalidade esportiva. Seja qual for essa atividade esportiva pretendida, os desafios e dificuldades a serem trilhadas serão bastante similares. Podemos dizer então que o atleta de alto rendimento é aquele que tem o esporte como profissão igual a qualquer outra profissão, com os mesmos benefícios, como carteira assinada, férias, $13^{\circ}$ salário etc.

Diferentemente do atleta de alto rendimento, o atleta que apenas pratica esporte, mas não tem o mesmo como profissão, não deixa de ser um atleta. Existem hoje escolas que preparam atletas para que alcancem o máximo desempenho, deste modo, os centros de alto rendimento desportivo procuram potenciar as diferentes capacidades dos desportistas. Isto implica o desenvolvimento de certas rotinas de treino para aperfeiçoar a condição atlética, a técnica, etc.

Sendo assim, em breves palavras os termos "Alto e Baixo Rendimento" tratamse de competitividade de um atleta e não esportes em particular. Um exemplo de um atleta de baixo rendimento seria alguém que pratica o esporte por lazer ou bem estar físico, sem se preocupar com o seu resultado no término da prova. Alto rendimento seria um atleta olímpico que vive de treinos diários e obrigações para se classificar bem em competições.

$\mathrm{Na}$ área do Crossfit percebemos que existem muitos atletas profissionais que se tornaram competidores de alto rendimento. Esse esporte se trata de um método de 
condicionamento físico e metabólico exigente que se tornou cada vez mais popular por ser um tipo de atividade física também um esporte competitivo. O objetivo final do Crossfit é maximizar e sustentar a produção de energia a cada treino (Smith et al, 2013).

É possível observar que atletas e praticantes da metodologia Crossfit não fazem ou não tem nenhum contato com um especialista da área da psicologia. Por esta razão são afetados em diversos aspectos, por exemplo: derrotas, vitórias, cobranças e até mesmo o pré e pós lesão. Muitos praticantes ou atletas são negligentes por não darem atenção a treinos preventivos às lesões como, mobilidade, fortalecimento e alongamentos, e quando ocorrem as lesões por estarem despreparados psicologicamente, acabam escondendo microlesões que podem se tornar uma lesão mais grave.

Observamos que isso acontece devido ao emocional do atleta. Geralmente ele pensa em ter que parar o treino por um período, o que contribuirá para a perda de resultados frente a outros atletas. Já em lesões graves e ou cirúrgicas observamos que muitos param de treinar, pois além de ficar muito tempo parado em tratamento tendem a voltar sem o mesmo condicionamento de antes. Isso proporciona uma sensação de que os atletas de Crossfit nunca mais voltaria ao seu nível normal ou até melhor, sendo que a ansiedade, a vaidade e a depressão não são trabalhadas corretamente por um profissional adequado.

\subsection{Um panorama geral sobre a psicologia do esporte no Brasil}

Existe no Brasil aqueles que acreditam que a psicologia do esporte é uma área nova do conhecimento. Talvez, o que seja novo é a atenção da própria psicologia e de outras áreas de estudo para com a psicologia do esporte. Poucos acervos são encontrados na literatura brasileira quando se trata de investigar as faces do esporte, salientando a importância de grandes reflexões e argumentações sobre esse episódio (GALATTI, 2010).

Weinberg e Gould (2017, p. 4) explicam a psicologia do esporte e do exercício como "um estudo científico de pessoas e seus comportamentos em atividades esportivas e atividades físicas". Trazendo uma visão um pouco mais ampla do conceito de psicologia do esporte e do exercício, descrevem Pesca e Cruz (2011, p.11) "a

Educação, Psicologia e Interfaces, Volume 4, Número 3, p. 1-16, Julho/Setembro, 2020.

ISSN: 2594-5343. DOI: 10.37444 /issn-2594-5343.v4i3.297 
psicologia do esporte é o estudo científico das pessoas e seus comportamentos no contexto esportivo e de exercício, bem como as aplicações práticas derivadas dos conhecimentos gerados por esses estudos".

Com base nesses pensamentos, podemos compreender que a psicologia do esporte possui um campo de intervenção e não apenas o conceito como uma ciência aplicada, o que amplia a nossa capacidade de atingir a compreensão acerca dos processos psicológicos utilizados nesse contexto. Para entendermos acerca do tema abordado dessa pesquisa, é necessário que se compreenda alguns fatos históricos sobre a psicologia do esporte, onde tudo se iniciou até os dias de hoje.

Considerado o que diz o pai da psicologia do esporte, Coleman Griffith, norteamericano que dedicou uma parte considerável de sua profissão à psicologia do esporte, por ter criado o primeiro laboratório de pesquisa, vemos que o mesmo ajudou a iniciar umas das primeiras escolas de técnicos nos Estados Unidos. Além disso, escreveu alguns livros e realizou uma série de estudos dentro da psicologia do esporte.

No Brasil, a psicologia do esporte ganhou forças com o trabalho e estudos desenvolvidos pelo experiente Psicólogo João Carvalhaes, que atuou em clubes como São Paulo Futebol Clube e na seleção brasileira de futebol em 1958. Foi convocado pela comissão técnica na disputa da copa do mundo nessa mesma época e conquistou o primeiro título mundial do País (RUBIO, 2000). Depois desse episódio, muitas outras coisas aconteceram para que a psicologia do esporte fosse estruturada e conquistasse seu espaço na história e na área de atuação.

A expansão da psicologia do esporte no Brasil como desenvolvimento emergente não tem correlação positiva com o desenvolvimento da psicologia como ciência e profissão. Talvez uma razão para o subdesenvolvimento possa ser buscada não apenas na psicologia do esporte, mas também na incerteza dos recursos disponíveis para o esporte. Por exemplo, não os psicólogos que praticam esportes, mas os verdadeiros psicólogos do esporte com treinamento geral e específico (CASAL, 2007). A escassez de estudos e prática da Psicologia do esporte afeta, de maneira significativa, o rendimento e desenvolvimento dos atletas. E isso dificulta o alcance de metas e desempenho adequado para conquistas grandiosas.

A psicologia do esporte, em vista disso, tem desbravado seu campo recentemente, principalmente no Brasil. E os anos 1990 foram o marco da introdução 
Adoecimento psíquico em atletas de alto rendimento: a importância da Psicologia do Esporte

do esporte como fenômeno social no país.

\subsection{O esporte como um fenômeno social: um breve panorama sobre as possibilidades e desafios na atuação profissional}

A psicologia, acompanhando o desenvolvimento da humanidade, tem promovido constantes revisões em suas teorias e amplia suas práticas, tentando encontrar respostas aos desafios que surgem com o progresso da sociedade. Assim, à medida que traz novas perspectivas de vida, também traz novos problemas a serem enfrentados pela ciência.

Pela constituição Federal, o esporte é um direito garantido a todos os brasileiros. Porém, a realidade o traz como uma ferramenta eletizada. Cada vez mais, Ong's tem procurado realizar um trabalho através do esporte, e este, visto de uma maneira sóciopolítica, pode ser um instrumento de interpretação da realidade. Por muito tempo a psicologia foi considerada altamente elitista e um serviço que poucos tinham acesso, mas com a popularização das faculdades do curso no país, e vários profissionais se formando, houve uma pequena massificação do serviço, o que fez com que outras classes sociais fossem atingidas e o lado social da população fosse observado.

Segundo Rúbio (2000), o esporte é hoje considerado um dos principais fenômenos sociais da era moderna. O esporte é uma forma elementar de socialização, até uma variante profissional. Forme a imaginação social. É identificado por elementos como força, passagem de fronteira, vitória e supremacia como autovalores que refletem o atual modelo social.

A partir deste aspecto, surge no pensamento popular que qualquer um pode alcançar o sucesso, desde que se esforce, que todos tem chances iguais. O esporte cresce porque é poupado de pobreza e marginalidade e é uma excelente maneira de divulgar projetos sociais que envolvem mídias sociais. A realidade não se mostra dessa forma. No esporte existem diversas classes sociais, assim como diversas deficiências.

Assim como o Brasil tenta se situar como uma nação que procura romper as desigualdades sociais, o esporte, como reflexo, percorre o mesmo caminho, pois, ao ser um grande fenômeno de massas, passou a ter como prioridade a rentabilidade e mercantilização.

Educação, Psicologia e Interfaces, Volume 4, Número 3, p. 1-16, Julho/Setembro, 2020.

ISSN: 2594-5343. DOI: 10.37444/issn-2594-5343.v4i3.297 


\subsection{Influências da mídia na cultura do esporte brasileiro: elucidações}

A veiculação de informações propagadas pela mídia podem interferir na vida do atleta, de maneira a agravar significativamente o seu estado mental, transformandoo em refém da própria imagem. Por esta razão procuramos, também, trazer esse tema para discussão neste trabalho. A mídia exerce uma expressiva influência sobre esse aspecto e na maioria das vezes transmite algo sobre a identidade de atletas como aspecto que o remete a uma figura mítica, um herói - e na maioria das vezes os personagens principais desse espetáculo visam, principalmente, a obtenção das grandes audiências e lucro.

Conforme argumenta Rúbio (2001, p. 3), "o espetáculo do esporte moderno e a superestimação dos resultados alcaçados do atleta sugerem uma relação entre o protagonista do evento esportivo e a figura espetacular do herói". Nesse sentido, entendemos o esporte como um fenômeno moderno que traz consigo os valores arraigados ao capitalismo que tornam o atleta como uma fonte de renda.

Por outro lado, entendemos que a audiência alcançada e os futuros lucros que a mesma pode proporcionar, segundo Nasário (2009, p.70), não se dá unicamente por meio da exibição em si e sim, por todo um aparato criado em torno da transmissão. Quando abordamos assuntos sobre esporte, e isso principalmente no Brasil, automaticamente o futebol vem em primeiro pensamento. Podemos falar que hoje é considerado uma das maiores paixões da cultura brasileira e um dos que mais movimentam dinheiro e grandes investimentos na indústria do esporte.

Sob outro olhar, Giglio e Rubio (2013) exibem que esse aspecto também prejudica o futebolista profissional, de modo que as promessas do jovem brasileiro mudam para matérias-primas em que suas atitudes dentro e fora de campo podem ser afetadas, porque são consideradas bens, frequentemente objeto de conflito, julgamento e perda da liberdade de expressão.

O modo como os jogadores se comportam no sistema de futebol e revelam suas idéias, bem como o apoio da mídia, será crucial para manter-se em evidência. Segundo Giglio e Rubio (2013), a estrutura do futebol brasileiro e do futebol mundial é projetada em ordens hierárquicas e respeitosamente, sem questionar a maneira pela qual o 
processo de organização do esporte ocorre, a mídia geralmente influência nas informações precisas sobre os estágios que cada jogador realiza.

O reconhecimento no futebol se da de forma rápida, e Cillo (2002) ressalta que isso pode ser um pouco negativo, porque muitos desses jovens ficam encantados com a nova realidade que é diferente. Confiam em pessoas que os darão as costas ao declínio profissional no futuro e, portanto, são vulneráveis às barreiras que a vida e o esporte lhes trazem. Mas, assim como a mídia pode ser um ferramenta propulsora no reconhecimento, e até mesmo a fama desses atletas, ela pode ser prejudicial à saúde psíquica desses - ponto de discussão da próxima seção do artigo.

\subsection{Adoecimento psíquico: análise de atletas que lidaram com a depressão}

Quando se pensa em adoecimento psicológico sofrido por atletas, a psicologia do esporte não pode deixar de considerar o avanço e espetacularização do esporte, em todo o contexto sociocultural contemporâneo. Por conta da inserção tecnológica tanto nos ambientes de iniciação esportiva e nos treinamentos quanto nas competições, o que se tem é um demonstrativo da importância do esporte naquilo que mais vulnerável temos hoje: o sistema financeiro (MACHADO, 2014). Praticar esporte, implica em falar em dinheiro; por consequência, a lesão é uma perda de dinheiro ou uma porção deste paralisada aguardando a recuperação.

A depressão no esporte advém de vários fatores que levam esses atletas ao adoecimento. As causas mais comuns da depressão nos atletas são: personalidade do atleta, ansiedade, baixa auto-estima, fracasso, lesão física, mudanças de comportamento, auto-cobrança, problemas afetivos, perda de prestígio ou da posição de titular, baixo rendimento, dentre outras causas.

Ao ver um atleta em um pódio, podemos pensar que "a vida dele é perfeita". Mas, na realidade não é bem assim. Dentro do esporte podemos destacar também alguns nomes de grande importância para o atletismo no Brasil e no mundo, pessoas que sofreram com esse adoecimento. Em entrevista publicada na Uol, alguns atletas relataram suas experiências e como lidaram com a depressão. Abaixo citamos alguns exemplos:

Anthony Ervin, nadador americano que aos 35 anos, mostrou que era possível 
dar a volta por cima. Em Sydney, em 2000, com apenas 19 anos, Ervin fez seu nome depois de ganhar ouro aos $50 \mathrm{~m}$ prata aos 4x100 m. No entanto, aos 22 anos, ele decidiu largar tudo devido à depressão: bebia muito e usava drogas, incluindo cocaína. Ele também tentou cometer suicídio com tranquilizantes.

Diego Hypólito, ginasta que inspirou os brasileiros quando finalmente ganhou uma medalha olímpica nas Olimpíadas do Rio em 2016, depois de uma queda nas Olimpíadas de Pequim em 2008 e em Londres em 2012. Ele perdeu $10 \mathrm{~kg}$ e foi hospitalizado.

Allison Schmitt, atleta de natação conquistou cinco pódios em Londres, e logo após começou a sentir os primeiros sintomas da depressão, não falava com ninguém sobre o que estava sentindo e com isso sua situação foi só agravando no decorrer do tempo: ansiedade, pânico e exaustão foram alguns dos sintomas sentidos. Somente quando Schmitt procurou ajuda psicológica, conseguiu falar abertamente sobre a experiência que teve com a depressão e a saúde mental de atletas. Recebeu apoio da família, treinador e amigos - inclusive o multicampeão Michael Phelps.

Michael Phelps foi o grande medalhista da história dos Jogos Olímpicos. Também teve que superar uma profunda depressão para terminar sua carreira em grande estilo. Em 2014, o nadador americano chegou ao fundo do poço quando se tornou viciado em pôquer, bebidas e drogas.

Rafaela Silva foi vítima de muitas críticas nas Olimpíadas de 2012 . Mais do que a tristeza pelo favoritismo ter virado uma eliminação nas oitavas de final, a judoca sofreu críticas fortes e até racistas. Rafaela começou um tratamento com a psicóloga Nell Salgado. Foi com o auxílio da terapeuta que a judoca conseguiu recuperar o foco e voltar a treinar.

\subsection{Contribuições do psicólogo no âmbito esportivo}

Pensando acerca das contribuições desse profissional no âmbito da prática, o primeiro passo a ser realizado é de forma dinâmica, avaliando as necessidades de cada atleta, para que se tenha o desempenho pleno da modalidade. Assim, indagamos: Quem é esse atleta? Como se insere nesse ambiente? Como ele atua? Temos que entender a demanda, mas não esquecendo que existe um ser humano por detrás de cada atleta. 
Nessa perspectiva, o psicólogo do esporte atua de maneira a identificar nos atletas a personalidade em primeira instância como fator de alteração dentro do ambiente esportivo. Para uma melhor comprensão acerca das respostas dos atletas em diferentes ocasiões no esporte, é necessário que se estabeleça condutas adequadas a cada indivíduo e treinos de habilidades psicológicas para melhorar o rendimento atlético.

Essa questão apresentada é um fator de muita influência, como por exemplo, a escolha de um capitão de um time, para que essa escolha seja realizada um quesito a ser avaliado, e também se realmente esse atleta tem perfil de um líder, se sabe lidar bem com as pessoas, se sabe conversar com as pessoas, dentre outras características. Segundo Weinberg e Gould (2017, p. 25) “personalidade é a soma das características que tornam uma pessoa única.

A motivação é outro fator de muita relevância no desempenho desse atleta. Para Weinberg e Gould (2017, p. 48) “motivação é a direção e a intensidade do esforço". A direção do esforço diz respeito ao fato do atleta buscar, aproximar-se ou ser atraído por certas situações ou não. Já a intensidade do esforço diz respeito a outro ponto. Ou seja, quanto uma pessoa se empenha em determinada situação. Podemos dizer, em breves palavras, que motivação é o que motiva a ação desse atleta. Como já citado, Weinberg e Gould (2017, p. 49) esclarecem que "a melhor maneira de entender motivação é considerar tanto a pessoa quanto a situação e o modo como ambas interagem".

A partir de tal citação, entendemos que os fatores pessoais, como a personalidade, interesses, necessidades em interação com os fatores situacionais, como por exemplo, estilo do líder-tecnico e histórico da própria equipe, se faz necessário para melhor entender sobre a motivação.

Além desses aspectos aqui apresentados, reconhecimos que existem atletas que gostam de atuar sob pressão, isso se torna um ambiente motivador, para outros lidar com a pressão pode lhe causar uma grande ansiedade acarretando prejuizos no desempenho desse atleta. Após identificar esses aspectos, se inicia a preparação desses atletas, como o treinamento de habilidaades psicológicas. Quantas vezes já não vimos atletas atribuirem o fracasso do seu desempenho a questoes como falta de concentração ou tensão sob pressao?

O conceito diante do treinamento de habilidades psicológicas que Weinberg e 
Gould (2017, p. 231) refere-se "à prática sistemática e consistente de habilidades mentais ou psicológicas com o objetivo de melhorar o desempenho, aumentar o prazer ou alcançar maior satisfação na atividade esportiva e física. As questões psicológicas são os principais responsáveis pelas oscilações no desempenho cotidiano e muitos atletas negligenciam esse aspectos, talvez pela falta de conhecimento, ou por equívocos em relação a habilidades psicologicas ou até mesmo pela falta de tempo de se fazer esses treinamentos. O motivo pelo qual isso ocorre é incerto, mas é uma ferramenta que se for utilizada de forma adequada, pode trazer grandes benefícios no desempenho de atletas.

Outra forma de treinamento e de grande importância a ser utilizada por psicólogos é a regulação da ativação, onde o primeiro passo nesse processo é aprender a identificar ou a ter consciência dos estados de ansiedade e de ativação como por exemplo lidar com as pressões nas competições. Nesse contexto, Weinberg e Gould (2017) explicam que, para isso, os atletas podem ser instruídos a rememorar seus melhores e piores desempenhos e recordar o que sentiram nessas ocasiões. Assim, o atleta poderá encontrar-se num estado que o desanimará completamente ou que o ativará em excesso, sendo essas duas condições prejudiciais à sua atuação (BECKER JUNIOR; SAMULKI, 2002).

A mentalizaçao é outra forma de treinamento segundo Weinberg e Gould (2017 p. 274), pois para eles o processo consiste em recuperar da memória fragmentos de informações armazenados de experiências passadas e molda-los em imagens significativas.

Autoconfiança é outro fator que pode ser trabalhado. É uma crença de que você pode realizar com sucesso um comportamento desejado (WEINBERG e GOULD, 2017). Você pode esperar que suas expectativas sejam configuradas automaticamente o pensamento subjetivo de uma pessoa sobre a execução de tarefas de maneira geral ou específica. Quando a autoconfiança é produzida em um nível ideal para um atleta, ela auxilia de maneira positiva no seu desempenho. (MACHADO, 2006).

A concentração também deve ser trabalhada. Nesse viés, Weinberg e Gould (2017) definem a concentração como "a capacidade de manter o foco em sinais ambientais relevantes. Quando o ambiente muda depressa, o foco de atenção também deve mudar rapidamente". Diante disso é a manutenção do foco de atenção também faz 
Adoecimento psíquico em atletas de alto rendimento: a importância da Psicologia do Esporte

parte da concentração, os atletas devem se concentrar apenas em fatos relevantes do ambiente esportivo eliminando qualquer distração que possa surgir.

Tendo em vista esses aspectos a serem trabalhados por profissionais da psicologia do esporte aqui apresentados, esse profissional é sem duvidas um agente primordial na qualidade e desempenho desses atletas. Um profissional inserido nesse ambiente atua não só de forma a trabalhar o adoecimento dessses atletas, como também na prevençao desse adoecer. Auxilia não só na superação de limites como na própria busca da identidade desse atleta.

\section{CONSIDERAÇÕES FINAIS}

O objetivo principal deste trabalho foi discutir a importância da atuação do psicólogo do esporte no trabalho com atletas de alto rendimento. A partir da discussão e análise que aqui elaboramos, tentamos responde-lo por meio das análises que seguem. Podemos observar, por um lado, que embora a psicologia do esporte seja considerada uma área nova do conhecimento, tendo em vista que já vem sendo estudada há muitos anos, nos deparamos com a escassez desses profissionais nos possíveis campos de atuação. Esse ponto, de certa maneira, dificulta o avanço das discussões nesse campo e o reconhecimento dessa área enquanto profissão. Por outro lado, esse fato pode tornar, na maioria das vezes, a inserção destes profissionais um pouco mais duvidosa e com pouca credibilidade nesta área do esporte.

Desse modo, entendemos que o profissional nesse âmbito esportivo ainda perpassa por grandes desafios, no sentido de se ter uma grande demanda e pouco espaço para explorar e colocar em prática seus conhecimentos. Tendo em vista essa nova área que envolve a psicologia do esporte, em ascensão, podemos refletir sobre possíveis aspectos que ainda estão por vir.

Considerando a possibilidade de intervenção do psicólogo do esporte no campo esportivo, indagamos: por que ainda é tão dificil a inserção desse profissional nessa área? O que podemos fazer para mudar essa realidade? Prováveis respostas para essas perguntas estão relacionadas, por exemplo, com a própria valorização desse profissional, bem como com a falta de investimentos na área das pesquisas sobre o assunto.

Educação, Psicologia e Interfaces, Volume 4, Número 3, p. 1-16, Julho/Setembro, 2020.

ISSN: 2594-5343. DOI: $10.37444 /$ issn-2594-5343.v4i3.297 
Portanto, reconhecemos que a atuação dos psicólogos é de extrema importância, uma vez que o rendimento esportivo também está relacionado ao trabalho voltado à questão psíquica dos atletas. Precisamos olhar esses atletas com um olhar mais humano e não apenas como um produto de obtenção de lucros e grandes investimentos. Estudos futuros poderão aprofundar em investigações que exploram questões metodológicas que envolvem o trabalho do psicólogo do esporte, uma vez que nas buscas realizadas para os selecionar as referências bibliográficas deste artigo, constatamos uma carência de discussões nessa área.

\section{REFERÊNCIAS BIBLIOGRÁFICAS}

BRANDÃO, M.R.F; MACHADO, A. A. (orgs). Coleção psicologia do esporte e do exercício: aspectos psicológicos do rendimento esportivo. São Paulo: Atheneu, 2008.

BECKER, H. Métodos de pesquisa em ciências sociais (pp. 117-133). São Paulo: Hucitec. Becker Junior, B. (2000). Manual de psicologia do esporte e exercício. Porto Alegre: novaprova.

BECKER JR, B.; SAMULSKI, D. Manual de treinamento psicológico para o esporte, 2.ed. Erechin: Fevale, 2002.

CASAL, H.M.V. (2007). Fatos e reflexões sobre a história da Psicologia do esporte. Em BRANDÃO, M. R. F. e MACHADO, A. A. Coleção Psicologia do esporte e do Exercício, v. 1. São Paulo: Atheneu.

CECARELLI, Lucas Ribeiro. Crônica de um fracasso anunciado: um estudo de caso a partir das narrativas disponíveis na mídia sobre psicologia do esporte na Seleção Brasileira de Futebol na Copa do Mundo de 2014. 2015. 89 f. Dissertação (mestrado) - Universidade Estadual Paulista, Instituto de Biociências de Rio Claro, 2015. Disponível em: <https://repositorio.unesp.br/handle/11449/126500>. Acesso em 22 de out. 2019

DOMINSKI, Fábio Hech; SIQUEIRA, Thais Cristina; SERAFIM, Thiago Teixeira Serafim; ANDRADE, Alexandro. Perfil de lesões em praticantes de CrossFit: revisão sistemática. Fisioter Pesqui. 2018;25(2):229-239

GALATTI, Larissa Rafaela, PAES, Roberto Rodrigues, DARIDO, Suraya Cristina. Pedagogia do esporte: livro didático aplicado aos jogos esportivos coletivos. Motriz, v. 16, n. 3, p. 751-761, jul./ set., 2010. Disponível em: < http://www.scielo.br/pdf/motriz/v16n3/a24v16n3.pdf > acesso em 10 de out. 2019 
MACHADO, A. A. Psicologia do esporte, Desenvolvimento humano e

Tecnologias: o que e como estudar. 1. ed. Várzea Paulista: Editora Fontoura, 2014.

GIGLIO, S. S. RUBIO, K Futebol: mitos, ídolos e heróis. 2013. 160 f. Dissertação (Mestrado em Educação Física) - Faculdade de Educação Física, Universidade Estadual de Campinas, Campinas, 2013.

MACHADO, A. A. Psicologia do esporte: da educação física escolar ao esporte de alto nível. Rio de Janeiro: Guanabara Koogan, 2006.

NASÁRIO, Júlio Cesar. Competição na educação física escolar: representação social de professores da educação básica. Blumenau, 2009. 85 p. Dissertação (Mestrado em Educação). Universidade Regional de Blumenau, SC. Disponível em: $<$ http://www.bc.furb.br/docs/DS/2009/336826_1_1.pdf > acesso em 10 de nov.2019

PESCA, A. D., \& CRUZ, R. M. (2011). Estudos de autoeficácia em psicologia do esporte. Revista de Psicologia, (1).

RUBIO, K. (2000) O trajeto da Psicologia do esporte e a formação de um campo

profissional.. Disponível em:

< http://www.ub.edu/geocrit/b3w-373.htm> acesso em 22 de out 2019.

RUBIO, K.; QUEIROZ, C.; MONTORO, F. C.; MARQUES, J. A; Kuroda, S. J. (1999) Iniciação esportiva e especialização precoce: as instâncias psicossociais presentes na formação esportiva de crianças e jovens. Revista Metropolitana das Ciências do Movimento Humano. 4 (1).

RUBIO, K. (1999). A psicologia do esporte: histórico e áreas de atuação e pesquisa. Psicologia: Ciência e Profissão, 19, 60-69. Rubio, K. (2000). Encontros e desencontros: descobrindo a psicologia do esporte. Casa do psicólogo Livraria e Editora Ltda. São Paulo, Casa do Psicólogo. Disponível em < http://www.scielo.br/pdf/pe/v15n2/a18v15n2.pdf > acesso em: 14 de out. 2019.

RUBIO, K. (2001) O trajeto da Psicologia do esporte e a formação de um campo profissional. Disponível em:

< https://repositorio.unb.br/bitstream/10482/20801/1/2016_HugoSoaresPinho.pdf $>$ acesso em: 14 de out. 2019

RUBIO, K (1999.) Psicologia do esporte: interfaces, pesquisa e intervenção. São Paulo: Casa do Psicólogo. Disponível em:

$<$ http://pepsic.bvsalud.org/scielo.php?script=sci_arttext\&pid=S1981-

91452007000100007> acesso em 02 de nov. 2019.

RUBIO, K. (2007). Ética e compromisso social na Psicologia do esporte.

Psicologia Ciência e Profissão. Disponível em: 
$<$ http://pepsic.bvsalud.org/scielo.php?script=sci_arttext\&pid=S141498932007000200011> acesso em 14 de out. 2019.

RUBIO, K . O atleta e o mito do herói: o imaginário esportivo contemporâneo. São Paulo: Casa do Psicólogo, 2001.

SAMULSKI, D. Psicologia do esporte: conceitos e novas perspectivas. Barueri: Manole, 2009.

SMITH, M. M., SOMMER, A. J., STARKOFF, B. E., \& DEVOR, S. T. Crossfitbased high-intensity power training improves maximal aerobic fitness and body composition. J Strength Cond Res, 27(11), 2013.

WEINBERG, R. S.; GOULD, D. Fundamentos da psicologia do esporte e do exercício. 6. ed. Porto Alegre: ArtMed, 2017.

\section{Credenciais da/os autora/es}

FRADES, Luane de Jesus. UNIFIMES, Centro Universitário de Mineiros. E-mail: luane.frades@gmail.com

OLIVEIRA, Evandro Salvador Alves. Doutor em Estudos da Criança pela Universidade do Minho (2020) - Portugal - linha de pesquisa: Educação Física e Saúde Infantil. Doutor em Educação pela Universidade de Uberaba (2019), Professor no Centro Universitário de Mineiros. E-mail: evandro@unifimes.edu.br

VAROLI, Bruno Manchini. Universidade de Londrina/Brasil. E-mail: bmvaroli@gmail.com

CARNEIRO, Cíntia de Moraes Cabreira. UNIFIMES, Centro Universitário de Mineiros. E-mail: cintia.carneiro@unifimes.edu.br

Endereço para correspondência: Luane de Jesus Frades. Rua 22 esq. c/ Av. 21 - St. Aeroporto, Mineiros - GO, 75833-130. E-mail: luane.frades@gmail.com

Como citar este artigo (Formato ABNT): FRADES, Luane Luane de Jesus, et al. Adoecimento psíquico em atletas de alto rendimento: a importância da Psicologia do Esporte. Educação, Psicologia e Interfaces, v. 4, n. 4, p. 1-16, 2020.

Recebido: 07/05/2020.

Aceito: 20/06/2020. 